\title{
PERSEPSI MASYARAKAT TERHADAP PENGEMBANGAN KAWASAN WISATA DI DESA KERTAWANGI, CISARUA KABUPATEN BANDUNG BARAT
}

\author{
Emron Edison ${ }^{(1)}$, Titing Kartika ${ }^{(2)}$, Nurul Dewi ${ }^{(3)}$ \\ (1) (2) (3) Sekolah Tinggi Ilmu Ekonomi Pariwisata Yapari \\ emron.bdg@gmail.com \\ nengtiting kartika@yahoo.co.id \\ deewinurul@gmail.com \\ Submitted:17 July 2019 Revised: 20 August 2019 \\ Accepted: 1 September 2019
}

\begin{abstract}
ABSTRAK
Pada dasarnya pengembangan pariwisata tidak terlepas dari peran masyarakat di sekitarnya. Dukungan dan peran serta masyarakat sangat diperlukan untuk sebuah pengembangan suatu kawasan wisata dan daya tarik wisata. Penelitian ini dilakukan di kawasan wisata Desa Kertawangi, Cisarua Kabupaten bandung Barat. Tujuan penelitian ini untuk mengetahui pengembangan kawasan wisata di Desa Kertawangi dan persepsi masyarakat terhadap pengembangan suatu kawasan wisata. Berdasarkan hal tersebut, kawasan wisata yang menawarkan daya tarik wisata tentu membutuhkan aspek-aspek dalam pengembangannya. Aspek-aspek tersebut adalah dengan pengembangan aktivitas dan daya tarik wistanya, trasportasi, akomodasi, elemen kelembagaan, insfrastuktur, dan pelayanan fasilitas wisata. Selain pengembangan, kemajuan dan kesejahteraan masyarakat menjadi penentu sebuah persepsi baik dari masyarakat. Peneliti menggunakan metode kombinasi melalui metode kualitatif sebagai metode primer dan metode kuantitatif sebagai metode sekunder. Hasil penelitian menunjukkan bahwa pengembangan kawasan wisata di Desa Kertawangi sudah berjalan dengan baik, hal tersebut dilihat dari berbagai aspek yang telah dikaji melalui observasi dan wawancara. Persepsi masyarakat mengenai kawasan wisata yang ada di sekitar daerah tempat tinggal mereka juga sudah baik, dilihat dari adanya peningkatan pendapatan masyarakat dan peluang usaha bagi masyarakat serta menambah lapangan pekerjaan namun belum signifikan.
\end{abstract}

Kata Kunci : Pengembangan, Kawasan Wisata, Persepsi Masyarakat

\section{COMMUNITY PERCEPTION TOWARDS TOURISM DEVELOPMENT AREA IN KERTAWANGI VILLAGE, CISARUA. WEST BANDUNG DISTRICT}

\section{ABSTRACT}

Basically tourism development is inseparable from the role of the local community. The community support and participation are needed for the development of a tourist area and tourist attraction. This research was conducted in the tourist area of Kertawangi Village, Cisarua, West Bandung Regency. The purpose of this study was to determine the development of tourist areas in Kertawangi Village and community perceptions of the development of a tourist area. That development, tourist areas that offer tourist attraction certainly need 


\section{Emron Edison, Titing Kartika, Nurul Dewi: PERSEPSI MASYARAKAT TERHADAP \\ PENGEMBANGAN KAWASAN WISATA DI DESA KERTAWANGI, CISARUA, KABUPATEN BANDUNG BARAT}

aspects in its development. These aspects are by developing activities and attractiveness of time, transportation, accommodation, institutional elements, infrastructure, and tourism facilities. In addition to development, progress and welfare of the community is a determinant of a good perception of the community. The researcher used a mix method through qualitative methods as primary methods and quantitative methods as secondary methods. The results of the study show that the development of tourist areas in Kertawangi Village has been going well, it is seen from various aspects that have been studied through observation and interviews. Community perceptions of tourist areas around their area of residence have also been good, seen from the increasing the community income and business opportunities for the community and increasing employment opportunities.

Keywords: Development, Tourism Area, Community Perception

\section{PENDAHULUAN}

Pariwisata merupakan sektor penting dan strategis bagi pembangunan, khususnya dalam usaha meningkatkan devisa negara, perekonomian daerah dan kesejahteraan masyarakat sekitarnya. Oleh karena itu, pemerintah daerah dan pemangku kepentingan lainnya, berlomba untuk mengembangkan potensi dan/atau meningkatkan kawasan wisatanya, mengingat pariwisata di Indonesia memiliki keindahan alam, keragaman budaya dan nilai-nilai sejarah yang menjadi daya tarik tersendiri.

Salah satu kawasan yang berkembang pesat dalam pengembangan pariwisata adalah kawasan Cisarua Kabupaten Bandung Barat, hal ini ditandai dengan banyaknya jumlah kunjungan wisatawan domestik maupun mancanegara. Kawasan ini terdiri dari beberapa desa, berdasarkan sumber BPS Kabupaten Bandung Barat (2016) terdiri dari: Desa Pasirhalang (2,92 km2); Jambudipa (1,45km2); Padaasih (7,62 km2); Kertawangi $(10,51 \mathrm{~km} 2)$; Tugumukti $(8,33 \mathrm{~km} 2)$; Pasirlangu (10,07 km2); Cipada (8,89 km2), dan; Desa Sidangmekar $(5,31 \mathrm{~km} 2)$. Secara keseluruhan luasnya $55 \mathrm{~km} 2$.

Berdasarkan penjelasan tersebut, desa terluas adalah Kertawangi. Desa Kertawangi dapat juga disebut sebagai kawasan tujuan wisata, hal tersebut telah memenuhi unsurunsur yang terkandung dalam UndangUndang Kepariwisataan Nomor 10 tahun 2009 di mana disebutkan bahwa, "segala sesuatu yang memiliki keunikan, keindahan, dan nilai yang berupa keanekaragaman kekayaan alam, budaya, dan hasil buatan manusia yang menjadi sasaran atau tujuan kunjungan wisatawan."

Dalam kawasan wisata yang ada di Desa Kertawangi di antaranya terdapat air terjun dalam bahasa sunda disebut "curug." Air terjun yang ada yaitu Curug Layung dan Curug Cimahi yang kini diubah menjadi Curug Pelangi. Selain Air terjun, yang tak kalah menariknya yaitu Dusun Bambu suatu kawasan dengan danaunya yang indah, lalu terdapat pula Natutal Hill penginapan yang berkonsep menyatu dengan alam dan sekaligus tempat outbond, dan satu lagi, yaitu destinasi baru yang ada di Desa Kertawangi yaitu Grace Rose Farm yaitu berupa taman bunga.

Seiring berjalannya waktu, kawasan wisata di Desa Kertawangi terus berkembang. Perkembangan tersebut secara langsung memberikan dampak dalam kehidupan masyarakat lokal melalui peluang usaha, seperti UKM, minimarket, jasa angkutan, dan lain sebagainya, namun terlihat belum memiliki penguatan ekonomi masyarakat disekitarnya secara signifikan. Padahal menurut Mill (2000), pariwisata dapat memberikan keuntungan bagi wisatawan maupun komunitas tuan rumah dan dapat menaikan taraf hidup melalui keuntungan secara ekonomi yang dibawa ke kawasan tersebut. 
Kawasan wisata menurut Ismayanti (2010), merupakan usaha yang kegiatannya membangun dan mengelola kawasan dengan luas tertentu yang dibangun atau disediakan untuk kepentingan dan memenuhi kebutuhan pariwisata. Kemudian disebutkan lagi bahwa hal-hal yang harus diperhatikan sebagai berikut: 1) Kemampuan untuk mendorong peningkatan perkembangan kehidupan ekonomi dan sosial budaya; 2) Nilai-nilai agama, adat istiadat, pandangan serta nilainilai yang hidup dalam masyarakat; 3) Kelestarian budaya dan lingkungan hidup; 4) Kelangsungan usaha pariwisata; 5) Tata ruang; 6) Rencana Induk Pembangunan Pariwisata Daerah.

Agar kawasan pariwisata menjadi unggul dan menarik, maka perlu adanya pengembangan. Namun demikian, "dengan berkembangnya pariwisata suatu industri, di daerah yang banyak dikunjungi wisatawan itu, kepribadian penduduk setempat menjadi aneh, mereka banyak meniru kebiasaan wisatawan yang datang, terjadi apa yang kita kenal demonstration effect terutama di pusatpusat kegiatan pariwisata dikembangkan" (Yoeti, 2016:2).

Pengembangan pariwisata akan berhasil dengan baik jika penerapan komponenkomponen pariwisata dilakukan secara integratif, yaitu: 1) Pengembangan menyangkut aktivitas dan daya tarik wisata; 2) Pengembangan tentang transportasi; 3) Pengembangan tentang akomodasi yang baik dan nyaman; 4) Pengelolaan tentang elemenelemen institusional; 5) Pengembangan tentang insfrastruktur; 6) Pengembangan tentang pelayanan dan fasilitas wisata lainnya (Inskeep dalam Keliwer, 2011).

Dalam pembangunan dan pengembangan sebuah kawasan wisata tentunya dalam perspektif perencana, terkadang sebuah kawasan wisata tidak berdampak positif dan bermakna apa-apa dari persepsi masyarakat. Dalam pandangan Robbins (2003), persepsi adalah sebuah proses yang ditempuh masingmasing individu untuk mengorganisasikan serta menafsirkan kesan dari indra yang dimiliki oleh manusia agar memberikan makna kepada lingkungan sekitar. Banyak faktor yang mempengaruhi persepsi, mulai dari pelaku persepsi, objek yang dipersepsikan serta situasi yang ada. Lebih luas, "public perception is the way in which public group perceive a subject" (Vos dan Schoemaker, 2006).

\section{METODE}

Penelitian ini dilaksanakan di kawasan wisata Kecamatan Cisarua, Desa Kertawangi, Kabupaten Bandung Barat. Metode penelitian yang digunakan oleh peneliti adalah metode penelitian kombinasi, menurut Creswell (2010), penelitian kombinasi merupakan pendekatan penelitian yang mengkombinasikan antara penelitian kualitatif dan penelitian kuantitatif.

Tabel 1

Desain Penelitian

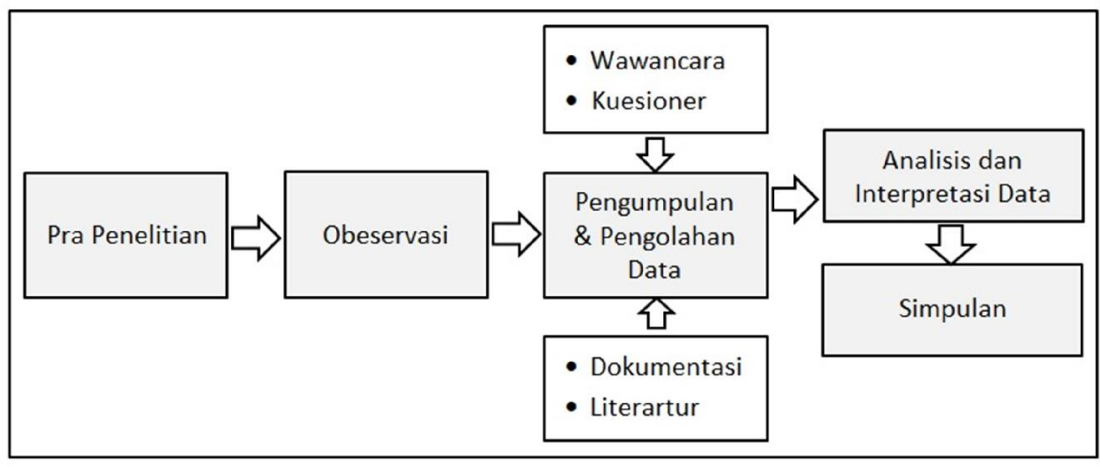




\section{Emron Edison, Titing Kartika, Nurul Dewi: PERSEPSI MASYARAKAT TERHADAP \\ PENGEMBANGAN KAWASAN WISATA DI DESA KERTAWANGI, CISARUA, KABUPATEN BANDUNG BARAT}

Pengumpulan data melalui observasi, wawancara, kuesioner, dokumentasi, dan studi literatur. Selanjutnya, data tersebut diolah dan diinterpretasikan sehingga menghasilkan simpulan. Dalam penelitian ini yang dijadikan sebagai narasumber adalah masyarakat di sekitar kawasan wisata, Kepala Desa Kertawangi, beberapa pihak pengelola kawasan wisata, yang merupakan informan kunci (key informant).

Dalam penelitian ini, peneliti menentukan beberapa informan kunci (key informant) yang akan dijadikan narasumber dalam pengambilan data, yaitu:

1. Masyarakat yang tinggal di sekitar kawasan wisata yang berada di Desa Kertawangi, Cisarua, Kabupaten Bandung Barat.

2. Kepala Desa Kertawangi, Cisarua, Kabupaten Bandung Barat.

3. Pengelola destinasi wisata yang berada di kawasan Desa Kertawangi, Cisarua, Kabupaten Bandung Barat.

\section{HASIL DAN PEMBAHASAN}

\section{Gambaran Kawasan Wisata Desa Kertawangi}

Gambaran tentang Desa Kertawangi

Kecamatan Cisarua Kabupaten Bandung Barat Provinsi Jawa Barat terkait dengan kawasan wisata dapat dilihat berikut ini.

1) Natural Hill

Natural Hill berlokasi di Jl. Kolonel Masturi Km 7 Cisarua, Kabupaten Bandung Barat, mempunyai luas area 14 hektar dan merupakan salah satu daya tarik wisata yang menarik milik perseorangan. Kawasan wisata ini berada di Desa Kertawangi. Dalam kawasan ini terdapat berbagai macam atraksi dan fasilitas yang disediakan di antaranya terdapat air terjun dengan pemandangan indah yang memiliki tinggi hingga 50 meter.

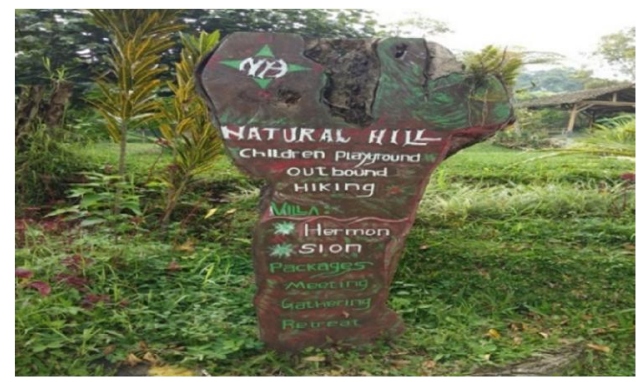

Gambar 1: Kawasan Natural Hill

2) Curug Layung

Curug Layung berada di Desa Kertawangi, terletak di bawah kaki gunung Tangkuban Perahu dengan suhu udara yang dingin dan sejuk. Daya tarik wisata milik Perhutani yang dibuka tahun 2012, dikelola oleh lembaga masyarakat lokal. Sebelumnya, tempat yang indah ini tertutup untuk umum karena mencakup wilayah khusus untuk latihan militer KOPASUS.

Menikmati pemandangan yang indah dan menghirup udara segar menjadi tujuan utama para wisatawan yang berkunjung ke Curug Layung. Menyajikan panorama dari arah utara, wisatawan yang berkunjung kesana dapat melihat luas hutan alami Gunung Tangkuban Perahu, di sebelah barat, terlihat jelas pemandangan Gunung Burangrang, sedangkan di arah selatan pemandangan pada tampilan Kota Bandung.

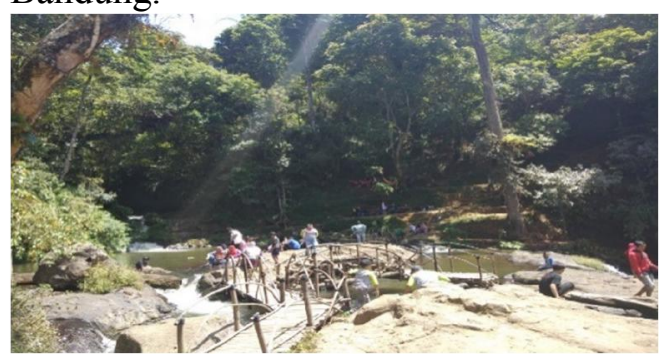

Gambar 2: Kawasan Curug Layung

3) Dusun Bambu

Dusun Bambu berada di Jl. Kolonel Masturi Km 11 Desa Kertawangi terletak di kaki Gunung Burangrang memiliki udara yang sejuk, jauh dari polusi dan kebisingan, serta memiliki keindahan dan keasrian alam yang mempesona. Kawasan dengan konsep ekowisata ini memiliki resort dari bahan kayu, dibelakangnya 
membentang danau yang indah, sangat cocok untuk kegiatan rekreasi keluarga. Selain itu, tersedia berbagai arena permainan seperti, arena trampolin, makan di tempat yang menyerupai sarang burung, naik perahu rakit, ada juga area untuk bermain dengan kelinci dan masih banyak yang menarik lainnya.

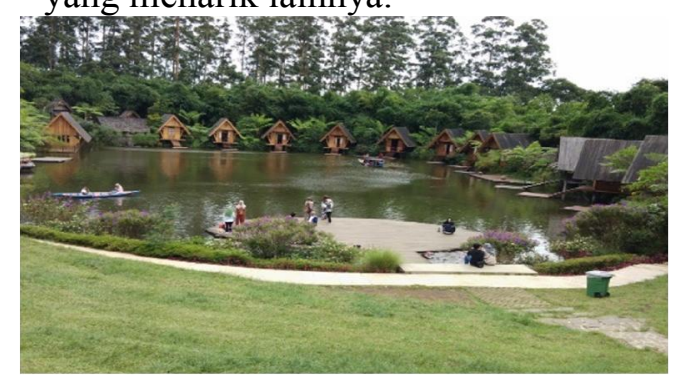

Gambar 3: Kawasan Dusun Bambu

4) Curug Cimahi/Curug Pelangi

Curug Pelangi nama air terjun yang berada di Jl. Kolonel Masturi Desa Kertawangi. Air terjun ini terletak di pinggir jalan raya Kolonel Masturi. Di daerah ini, masih banyak primata, monyet ekor panjang, monyet-monyet ini merupakan daya tarik yang melengkapi keutuhan dari keindahan yang ada. Air Terjun (Curug Pelangi) yang dikelola oleh Perhutani ini, saat sore dan malam hari air terjun ini diterangi oleh lampu-lampu sehingga sangat mengagumkan.

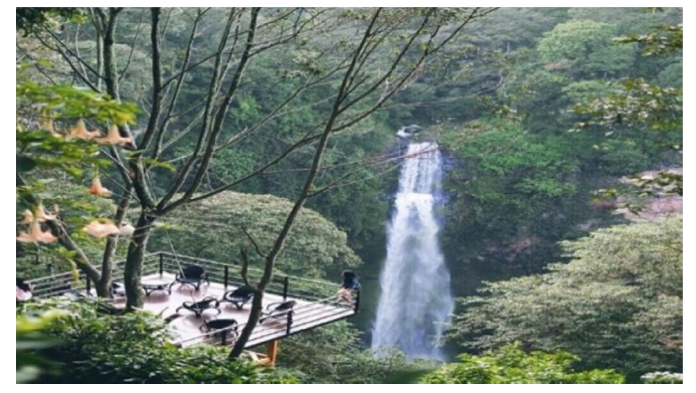

Gambar 4: Kawasan Curug Pelangi

5) Grace Rose Farm

Grace Rose Farm terletak di Jl. Kolonel Masturi Desa Kertawangi, Cisarua, terletak tidak jauh dari Curug Pelangi. Grace Rose Farm adalah wisata taman bunga dan kuliner khas Jawa Barat yang memiliki luas 5 hektar. Di kawasan wisata ini, selain menikmati keindahan beragam jenis bunga, tempat ini juga merupakan sarana edukasi untuk budidaya tanaman sayur, tanaman obat atau tanaman hias dan lainnya, sehingga dapat menambah wawasan wisatawan yang berkunjung.

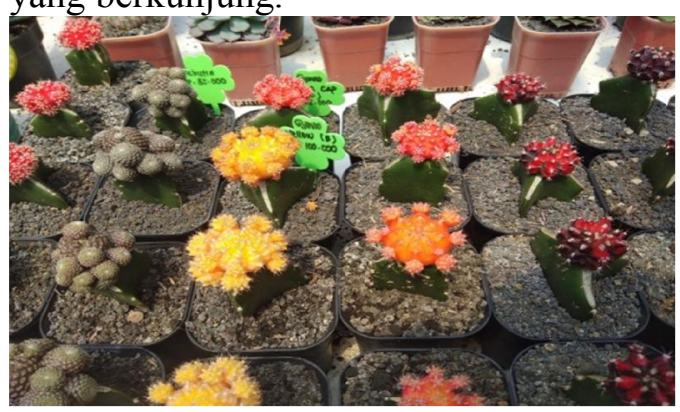

Gambar 5: Kawasan Grace Rose Farm

2. Pengembangan Kawasan Wisata di Desa Kertawangi, Cisarua Kabupaten Bandung Barat.

Dari hasil observasi dan wawancara peneliti dengan aparat Desa Kertawangi, Cisarua dilihat dari ke enam aspek keseluruhan bahwa pengembangan kawasan wisata di Desa Kertawangi sudah berjalan dengan baik, hal tersebut dapat dilihat dari enam aspek yaitu:

1) Aspek Pengembangan Aktivitas dan Daya tarik wisata sudah baik, dilihat dari pembangunan daya tarik buatan untuk mendukung aktivitas/kegiatan di kawasan wisata Desa Kertawangi. Semua pengembangan tersebut tujuannya adalah untuk lebih menarik wisatawan berkunjung dan mendapatkan pengalaman yang menarik. Selain adanya aktivitas wisatawan, terdapat aktivitas masyarakat yang berjualan di dalam maupun luar objek daya tarik wisata yang memanfaatkan dan menjadi kan peluang usaha bagi mereka.

2) Aspek Transportasi telah memadai, dikarenakan sudah tersedia pangkalan ojek, adanya terminal angkutan umum, area parkir yang luas dan sebagainya sehingga dapat memudahkan wisatawan untuk berkunjung ke sana. 
3) Aspek Pengembangan Akomodasi yang baik dan nyaman sudah tersedia akomodasi tersebut berupa resort, villa dan camping ground.

4) Aspek Kelembagaan di kawasan wisata Desa Kertawangi juga sudah tersedia yaitu LMDH (Lembaga Masyarakat Desa Hutan), LMDH merupakan lembaga yang mengelola curug layung bersama Perhutani unit III.

5) Aspek Pengembangan Insfrastruktur sudah memadai, keadaan jalan sudah baik, tidak berbatu dan berlubang, hanya ada satu akses menuju ke daya tarik wisata yang masih terjal dan berbatu, listrik sudah menyebar dan pasokan air bersih pun sudah ada.

6) Aspek Pengembangan pelayanan dan fasilitas di kawasan wisata Desa Kertawangi sudah cukup baik, hal ini dilihat dari adanya fasilitas-fasilitas yang sudah di sediakan seperti toilet, mushola, petunjuk arah, restoran dan sebagainya.

Dari enam aspek tersebut, yang paling pesat pengembanganya berada pada aspek aktivitas dan daya tarik wisata, hal itu ditunjukkan dari semakin tingginya tingkat kunjungan wisatawan ke kawasan wisata Desa Kertawangi dari tahun ke tahun. Dengan banyaknya wisatawan yang berkunjung, masyarakat sekitar memanfaatkan kondisi tersebut untuk melakukan aktivitas berjualan di area kawasan wisata tersebut.

Meskipun terdapat pengembangan yang pesat, namun masih ada yang perlu ditingkatkan, diantaranya perlu didirikan kelembagaan seperti membentuk lembaga Kelompok Sadar Wisata (POKDARWIS). Di dalam keanggotaannya terdiri dari masyarakat desa sekitar, dan didukung oleh pelaku kepariwisataan yang memiliki kepedulian tinggi dan tanggung jawab serta berperan sebagai penggerak untuk mengembangkan kawasan wisata dalam mewujudkan sapta pesona yang pada akhirnya dapat meningkatkan perekonomian desa dan masyarakat sekitarnya secara signifikan.

\section{Persepsi Masyarakat terhadap Pengem- bangan Kawasan Wisata di Desa Kertawangi, Cisarua Kabupaten Bandung Barat}

Dari hasil kuisioner yang dibagikan kepada 138 responden, secara keseluruhan menunjukkan bahwa persepsi terhadap Pengembangan Kawasan Wisata di Desa Kertawangi, Cisarua Kabupaten Bandung Barat mempunyai jumlah skor 456 dan berada di kategori "baik."

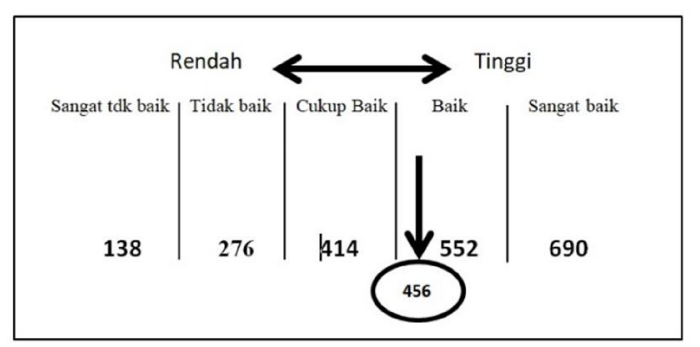

Gambar 6: Skala Rentang Penilaian

Masyarakat menerima adanya pengembangan kawasan wisata di daerah tempat tinggal mereka. Namun perlu ada perhatian mengenai beberapa hal yakni: (1) Budaya lokal sebagai daya tarik masyarakat belum cukup baik karena nilainya tergolong diangka 379, hal tersebut karena tidak adanya budaya lokal yang signifikan untuk dijadikan sebagai daya tarik wisata di Desa Kertawangi; (2) Dari aspek penurunan kemiskinan (peningkatan kesejahteraan) tergolong diangka 329, hal ini menunjukkan bahwa, kawasan wisata di Desa Kertawangi belum memiliki peranan signifikan dalam meningkatkan perekonomian masyarakat sekitarnya. Untuk itu pihak pengelola wisata dan pemangku kepentingan perlu memikirkan rencana untuk menyejahterakan masyarakat melalui pemberdayaan masyarakat disekitarnya.

\section{KESIMPULAN}

\section{Gambaran kawasan}


Kawasan wisata di Desa Kertawangi meliputi: Natural Hill; Curug Layung; Dusun Bambu; Curug Cimahi/Curug Pelangi, dan; Grace Rose Farm merupakan kawasan wisata yang menarik dan saling melengkapi dalam satu wilayah, sehingga perlu dibangun pola perjalanan wisata yang sinergi, tidak bersifat parsial. Dengan dibangunnya pola perjalanan sebuah kawasan yang saling bekerja sama dengan pemangku kepentingan akan memperkuat citra kawasan itu sendiri.

\section{Pengembangan Kawasan Wisata.}

Pengembangan Kawasan wisata di Desa Kertawangi sudah berjalan dengan baik dan sangat pesat hal tersebut dapat dilihat dari keenam aspek yaitu 1) Pengembangan menyangkut aktivitas dan daya tarik wisata., 2) Pengembangan tentang transportasi 3) Pengembangan tentang akomodasi., 4) Pengelolaan tentang elemen-elemen institusional., 5) Pengembangan tentang insfrastruktur., 6) Pengembangan tentang pelayanan dan fasilitas wisata lainnya. Namun, dalam insfrastruktur masih terdapat jalan yang harus diperbaiki karena jalan tersebut berlubang dan dapat membahayakan wisatawan yang berkunjung.

\section{Persepsi Masyarakat.}

Secara keseluruhan dapat disimpulkan, dimensi di dalam persepsi masyarakat dari perspektif Ismayanti (2010) yaitu: Secara keseluruhan Persepsi terhadap Pengembangan Kawasan Wisata di Desa Kertawangi, Cisarua Kabupaten Bandung Barat mempunyai jumlah skor 456 dan berada di kategori yang baik. Masyarakat menerima adanya pengembangan kawasan wisata di daerah tempat tinggal mereka. Namun perlu ada perhatian mengenai beberapa hal yakni: (1) Budaya lokal sebagai daya tarik masyarakat belum optimal, masih dalam katagori "cukup baik" dengan skor 379 , mengingat budaya lokal belum signifikan dijadikan sebagai daya tarik wisata; (2) Dari aspek penurunan angka kemiskinan masyarakat di Desa Kertawangi Cisarua skor 329 hal tersebut menunjukan bahwa, dengan adanya kawasan wisata di
Desa Kertawangi belum memiliki perananan signifikan dalam meningkatkan kesejahteraan masyarakat disekitarnya, untuk itu pihak pengelola wisata dan pemangku kepentingan perlu memikirkan konsep pemberdayaan masyarakat secara komprehensif.

\section{DAFTAR PUSTAKA}

Creswell, J. W. (2010). Research design: pendekatan kualitatif, kuantitatif, dan mixed. Yogjakarta: PT Pustaka Pelajar.

Ismayanti. (2010). Pengantar Pariwisata. Bandung: Alfabeta.

Keliwer S, \& Inskeep E. (2011). Tourism Planning: an integrated and Sustainable Tourism Development. New York: Van Nostrand Reinhold.

Mill, Robert C. (2000). Tourism The Internasional Bussiness. Jakarta: PT. Grafindo Persada

Robbins, S. P. (2003). Perilaku Organisasi. Edisi Sembilan. PT Indeks, Jakarta.

Vos, M. \& Schoemaker, H. (2006). Monitoring Public Perseption of Organisations. Amesterdam: Boom onderwijs

Yoeti, O. A. (2016). Perencanaan \& Pengembangan Pariwisata. Jakarta: Balai Pustaka 